\title{
MILLET SEED OR SAGO GRAIN URETHRITIS
}

\author{
By A. O. F. ROSS, M.D., D.P.H.
}

THIs comparatively rare form of urethritis can, as a rule, only be diagnosed by the use of the urethroscope, although in one of the cases to be described the use of this instrument was unnecessary since the millet seed bodies were present in the fossa navicularis and visible through the meatus. The ætiology is unknown, but of late years various writers have shown that a certain relationship exists between Waelsch urethritis, ${ }^{9}$ of which this clinical entity appears to be a variety, and lymphopathia venerea (climatic bubo, lymphogranuloma inguinale).

The clinical picture is that of a low urethritis. There is no scalding on micturition and the urethral discharge is small in amount, thin in consistence and as a rule white in colour. Gonococci are not found in smear or culture and no specific organism can be identified. The condition drags on from month to month and remains unaltered by antiseptic lavage treatment. The use of Kollmann dilators has been recommended by some urologists, but in the case in which this treatment was used no benefit resulted.

The urethroscopic picture is very definite. From the membranous urethra to the meatus there is a general hyperæmia of the mucosa and in the mucosa there are seen small oval bodies superficially placed, greyish yellow in colour, which are definitely not encysted follicles, and there is no special inflammatory change around these bodies. Glingar ${ }^{1}$ calls this condition " Urethritis cystica erythematosa" and differentiates it from Oberländer's follicular urethritis. He states that in Oberländer's follicular urethritis there is always infiltration of the mucous membrane which appears dry and anæmic. In Oberländer's follicular urethritis the cysts are formed by fibrotic changes around the ducts of Littre glands with consequent obstruction to the evacuation of the contents 
of the glands. He suggests that the name " Urethritis cystica indurativa" would describe the condition. In my opinion Oberländer's " Urethritis cystica indurativa " is a condition which results from chemical trauma in which the use of the small hand syringe plays a most important part. I have never seen it in a case of gonorrhœa which has been treated by lavage with weak antiseptic solutions from the beginning but have frequently found it in cases where a patient has treated himself with antiseptics of unknown strength by means of the small hand syringe. Urethritis cystica erythematosa on the other hand is not a complication of gonorrhœa, but is a condition which remains as it begins. It is in fact a definite urethral disease of unknown origin, probably due to some virus. One is of the opinion that the millet seed bodies or cysts are in the epithelium while in the case of follicular retention cysts the cyst extends into the submucous area.

Bezecny ${ }^{2}$ described a case of millet seed urethritis in which he had used the urethral exudate, after suitable preparation, as an antigen in cases of lymphopathia venerea. It was prepared by the same process as the necrotic material of climatic bubo had been prepared and used by Frei. Five cases of lymphopathia venerea were tested by the prepared urethral secretion and by Frei antigen. In 4 cases positive reactions to both were obtained and in one case Frei antigen gave a weak positive reaction while the urethral secretion gave a negative reaction. Twelve control cases were negative to both test preparations.

Similar results have been obtained with urethral secretion from abacterial urethritis Typus Waelsch by Curth, ${ }^{3}$ Frei, Wiese and Klestadt, ${ }^{4}$ Kalz, ${ }^{5}$ Polak and Gray. ${ }^{7}$ On the other hand neither Frei antigen nor prepared urethral secretion as a general rule gives a positive reaction in cases of Urethritis Typus Waelsch, nor will secretion from Urethritis Typus Waelsch produce meningo-encephalitis in mice, although necrotic material from climatic bubo characteristically does so. Fahlhusch and Zierl ${ }^{8}$ have suggested that urethral secretion from cases of Waelsch urethritis is more readily obtainable than necrotic material from climatic bubo and might supplant true Frei antigen, especially if it is found that false positive results are not obtained in young tuberculous 
subjects, a pseudo-reaction which occasionally occurs in Frei testing.

Frei, quoted by Bezecny, sums up the possibility of inter-relation between Waelsch urethritis and lymphopathia venerea as follows :-

(I) The urethritis may be due to an organism related to the filterable virus of lymphopathia venerea.

(2) The urethritis may be caused by an identical micro-organism to that of lymphopathia venerea. This is unlikely because the urethral secretion does not cause meningoencephalitis in experimental animals.

(3) The reaction produced by prepared urethral secretion in cases of lymphopathia venerea is non-specific and may be analogous to the reaction produced by agar in syphilitics positive to the Luetin test of Noguchi.

Two cases of millet seed urethritis have been diagnosed in Liverpool Clinics in the past eight years. Since all cases of urethritis which are slow in responding to treatment are brought to my notice and are urethroscoped, the rarity of the condition can be gauged. Both cases show the protracted nature of the disease and the absence of any specific ætiology.

Case I.-Shop assistant, married, aged 33 years. English. Gonorrhœea I926. Denies illicit intercourse since marriage five years ago. 26/4/35. Reported at Royal Infirmary Clinic complaining of urethral discharge of a few days' duration. The meatus was very inflamed and indurated and there was considerable crusting of the purulent urethral discharge.

Urethral smear showed much pus but no organisms beyond a very few diphtheroid bacilli and subsequent smears while showing much pus contained no organisms. Wassermann reaction was negative on five occasions during the next twelve months. The urine showed large quantities of muco-pus and no treatment by local irrigation or oral antiseptics caused any change. Hexamine 5 grains t.d.s. caused hæmaturia.

The meatus continued to be markedly indurated and on August 28th, I935, millet seed bodies were seen immediately within the meatus. Kollmann dilators were then employed at weekly intervals, but by October 3oth it became impossible to pass the instrument owing to the turgid condition of the urethral mucosa. Faute de mieux sulpharsphenamine $0.3 \mathrm{gm}$. intramuscularly was begun 
on November I3th and continued at weekly intervals until I 8 doses had been given. After the IIth dose the millet seed bodies disappeared and the urine cleared. No further signs or symptoms appeared and cure was presumed on June roth, 1936.

On November I6th, I938, the patient returned and since the urine was clear, the urethroscope was passed. The mucous membrane was normal and no millet seed bodies were seen. An endodermal injection of Frei antigen (Human) produced no reaction. Since Frei positive cases never cease to react to Frei antigen, it is probable that the patient would not have reacted even during the acute stage of his urethritis.

This case is notable for its acute nature and for the induration about the meatus which raised the question of syphilitic infection. The continued negative Wassermann reaction over a period of a year disproved the presence of syphilis.

Case 2.-Ship's officer, 26 years old, Canadian. No history of previous V.D. 4/10/38. Referred from the ship's surgeon with a history of mucopurulent discharge since July which had resisted irrigation and the usual methods of treatment. No gonococci had been found in any of the urethral smears and patient was becoming markedly neurotic and depressed. Patient denied intercourse with any woman not of his own class, and that but rarely. The last intercourse occurred in Canada in May, I938 and his consort was an old friend.

ExAmination.-Patient was a tall muscular man, but intensely worried about his condition. There were no signs of previous disease and his skin and visible mucous membranes were without blemish. The inguinal glands were palpable but not abnormal. There was a thin mucopurulent urethral discharge which stained the underlinen a pale lemon yellow colour in small spots. No thickening of the urethra was palpable. The urine contained excess mucus but no definite shreds. The prostate was normal to the palpating finger and the exudate was of the usual colour and consistency. Urethroscopy showed a moist glistening mucous membrane somewhat hyperæmic with some thirty or more millet seed bodies superficial in site in both the bulbous and penile portions.

Tests and Results.-Wassermann, Meinicke and I5O 
G.C.F.T.-negative. Culture of urethral secretion-no gonococci grown.

SMEARS.- - Urethral and prostatic.-A few pus cells and epithelial cells. No gonococci seen.

Treatment.-Oral only. M. and B. 693. Six tablets daily. Patient proceeded to sea the day following examination and was not seen again until October 3Ist. In the interval Dr. G. M. Findlay kindly supplied ampoules of Frei antigen (Human). 3I/Io/38. Patient reported that after taking M. \& B. 693 for twenty-four hours all discharge ceased and that on one or two occasions only was there slight glueing of the meatal lips in the morning. No urethral discharge could be obtained and urethroscopic examination showed a normal anterior urethra.

Frei antigen was injected endodermally and at fortyeight hours a papule $0.5 \mathrm{~cm}$. in diameter with a slight areola of erythema had developed. At eighty-eight hours the papule was still present but the erythema had disappeared.

The patient was asked not to micturate from Io p.m. till seen at 9 a.m. the following day. The urethra was washed with 2 c.c. of sterile normal saline and the washings were forwarded to Dr. G. M. Findlay, at the Wellcome Bureau of Scientific Research, for animal experiment. As the disease was apparently completely cured no positive results were expected. Dr. Findlay reported that " One of the mice directly inoculated with the washings appeared sick, but on passing the brain of this mouse into others we got no untoward result."

The patient was seen again one month later and again all tests and examinations proved negative.

It was unfortunate that this patient proceeded to sea before his pathological urethral secretion could be tested by animal inoculation and as an antigen in known cases of lymphopathia venerea, especially in view of the fact that a positive Frei cuti-reaction was obtained. If the urethral secretion had been collected at the first visit and had given rise to meningo-encephalitis in experimental animals there would have been evidence of the identical ætiology of the two conditions. As it is, one must assume that either the positive Frei test was purely incidental and similar to the reactions which occur in tuberculous subjects $^{8}$ or that the patient had previously suffered 


\section{BRITISH JOURNAL OF VENEREAL DISEASES}

from lymphopathia venerea, of which there was no history and no evidence, or that it furnishes further proof of the close relationship between millet seed urethritis and lymphopathia venerea. Bezecny ${ }^{2}$ has shown that the urethral secretion of millet seed urethritis causes a cuti-reaction in sufferers from lymphopathia venerea but in the present case the converse reaction has been demonstrated, namely that the autoclaved emulsified necrotic material (Frei antigen) obtained from the bubo of a case of lymphopathia venerea has provoked a cutireaction in a patient suffering from millet seed urethritis. In addition it is suggested that in M. \& B. 693 there exists a potent means of oral therapy for a most recalcitrant condition.

\section{REFERENCES}

(I) Glingar, A. (I932) : Ztschr. f. Urol., 26, 246.

(2) Bezecny, R. (I934): Med. Klin., 30, I2I. Quoted from HARrison, L. W. (I934): Rev. Bull. Hygiene, 390.

(3) Curth, W. (I93I): Med. Klin., 27, II76.

(4) FreI, W., WiESE, J., and KLESTADT, F. (I932) : Klin. Wschr., 11,

(5) KAlz, F. (I933): Med. Klin., 29, I678. 2 II4.

(6) Polak, H. J. (I933) : Derm. Wschr., 96, 233.

(7) GRAY, L. A. (I936) : Surg. Gynec. Obstetr., 62, 745.

(8) Fahlbusch, W. and ZIERL, R. (I937) : Dermat. Wschr., 105, II77.

(9) Waelsch, L. (I9OI): Prager. Med. Wschr., S.43. 